\title{
Mean what you say
}

\author{
Promises about job creation in the US stimulus bill \\ may be coming home to roost, says David Goldston.
}

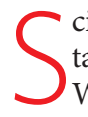
cientists may be about to learn an important, and perhaps surprising, lesson about Washington: words matter. Rhetorical strategies crafted to push a particular bill affect expectations about the impact of that measure and can take on a life of their own. The stimulus package that became law in February, and will provide more than US $\$ 21$ billion for research and development, is a case in point.

The Obama administration, Congress and advocacy groups sold the stimulus package to each other and to the public primarily as a way to create and retain jobs in the near future. The research funding in the bill was no exception, even though it was understood it could also promote longer-term economic growth. Congressman Rush Holt (Democrat, New Jersey), a physicist and a strong advocate for the research spending in the package, made the political linkage between research and jobs clear when he spoke at a conference on R\&D priorities in Washington DC last month. Holt said that the Democratic leadership had asked for data showing the impact the research spending would have on jobs before agreeing to up the funding for science agencies in the bill. Such data, he said, were not readily available, although after some scrambling, agencies were able to cobble together rough figures sufficient to carry the day.

But the data question is not about to go away. Indeed, the stimulus bill (now the Recovery Act) means that gathering data on the shortterm impact of research spending on jobs is about to become a preoccupation of the federal science agencies and their beneficiaries. Under the act, each grant recipient is required to report to the government quarterly on the number of jobs created and the number retained as a result of the stimulus money. The White House Office of Management and Budget is developing guidelines that will govern exactly how this information will be calculated, gathered and made public. But it's already clear that the reporting will probably go beyond existing efforts, in which agencies collect information, at most, about how many individuals were supported by a grant.

There's an old saying that what you measure is what you get. So, will this focus on near-term job creation change the way science agencies go about their business or how they're

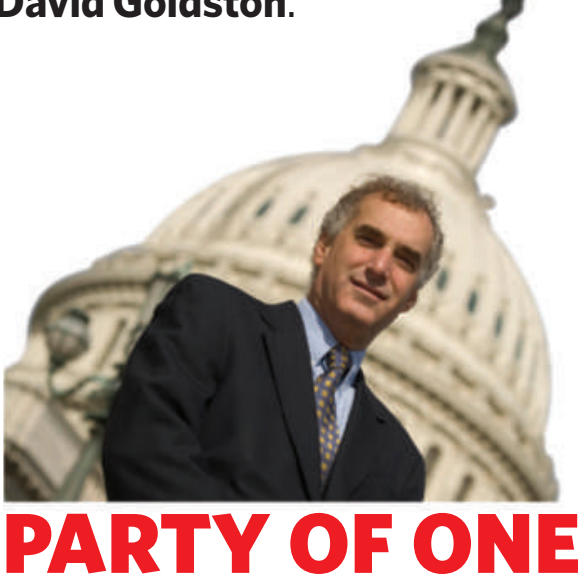

evaluated? It could. At a recent hearing of the House Committee on Science and Technology, Congresswoman Kathy Dahlkemper, a firstterm Democrat from an economically hardhit section of Pennsylvania, asked whether science agencies were "taking into consideration what areas of the country have the greatest need for job creation" when awarding stimulus funds. This would be a poor way to distribute the stimulus money, but it's not a ridiculous question to ask about a law that was explicitly presented as a way to create jobs now.

And the agencies' answers showed how much the rhetoric around the law is shaping their actions and how much fodder could end up being provided for future debates. Cora Marrett of the National Science Foundation (NSF) said her agency had mapped out where proposals already in hand that could be considered under the Recovery Act had come from, and that the NSF wanted to be sure it was "addressing needs, as those might vary across the country". Matthew Rogers of the Department of Energy said that "every dollar under the Recovery Act is associated with" a specific number of jobs, a state and an impact, adding that job creation and retention would be tracked by congressional district.

Concern about the geographical distribution of research funding is not new; whether federal dollars would flow almost exclusively to oldline Northeastern universities was a subject of debate when Congress created the NSF in 1950. And complaints about the geographical concentration of federal science money have been among the justifications for congressional earmarks - money Congress directs to specific projects at locations or institutions it selects.
Indeed, the number of academic earmarks has skyrocketed in part because of a previous rhetorical gambit. In the 1980s, the scientific community began describing universities as economic development tools because money was being handed out to spur 'competitiveness'. But associating individual grants with specific metrics about employment and considering near-term job creation as a rationale, or even a criterion, for making awards takes this line of thinking further than it's ever gone before. And all the information on jobs will be readily available on the web, displayed to a public that is in a sceptical and populist mood in the wake of bonus payouts to financial companies.

The Recovery Act is also prompting efforts to develop more rigorous economic analysis of the impact of science spending on jobs. The NSF's Science of Science and Innovation Policy Program has issued a call for proposals for research to evaluate the impact of the stimulus bill including such questions as: "What was the contribution of the science investment to the creation and retention of jobs?" (In the worst-case scenario, the lack of data about job creation will be replaced by clashing economic theories about it.)

Immediate job creation will not be the sole measure of the success or failure of the stimulus package, although it will no doubt be the most politically salient metric. But even broader means of evaluating the Recovery Act have a short-term focus because of the way the bill was sold. At the science committee hearing, Brad Miller, the North Carolina Democrat who chaired the session, said that "when the stimulus funds run out next year", Congress will want to know "did they provide investments needed to increase economic efficiency, by spurring technological advances in science and health". That may not be easy to know after just two years. The NSF research programme is also interested in proposals exploring "what scientific or technological advances" were achieved with the stimulus funds, but doesn't necessarily expect such advances to show up immediately.

It's obviously too soon to know whether the stimulus experience will change the way science funding is viewed in a significant or lasting way. And the pressures will vary depending on each agency's mission. But it is soon enough to conclude that the stimulus debate has underscored the importance of an oft-forgotten lesson in Washington: when you come up with a line of argument, think about what would happen if people actually believed you.

David Goldston is a visiting lecturer at Harvard University's Center for the

Environment. Reach him at partyofonecolumn@gmail.com

See also page 556. 